\title{
PRIMARY EXTRAUTERINE ENDOMETRIAL STROMAL SARCOMA- PELVIC PERITONEUM- REPORT OF A RARE CASE
}

Krishna Govindan Balachandran Nair1, Syamini Chandrasekharapillai Leelamany²

1 Professor and HOD, Department of Pathology, Government Medical College, Thiruvananthapuram, Kerala, India.

2Junior Resident, Department of Pathology, Government Medical College, Thiruvananthapuram, Kerala, India.

HOW TO CITE THIS ARTICLE: Nair KGB, Leelamany SC. Primary extrauterine endometrial stromal sarcoma-pelvic peritoneumreport of a rare case. J. Evolution Med. Dent. Sci. 2019;8(16):1355-1357, DOI: 10.14260/jemds/2019/301

\section{PRESENTATION OF CASE}

A 62-year postmenopausal female patient presented with abdominal pain for 3 month and mass per abdomen for 1 month. There was no history of hormone replacement therapy. On per abdominal examination, palpable mass of 10 $\mathrm{x} 10 \mathrm{~cm}$ on right lumbar and iliac region was noticed.

CECT abdomen showed irregular right sided abdominopelvic mass lesion with heterogeneously enhancing solid portion, fat and irregular calcification, poorly demarcated from adjacent small bowel loops, lateral abdominal wall and psoas muscle, medially displacing right ureter causing mild hydronephrosis.(Fig 1). Uterus was atrophic. Bilateral ovaries were normal.

\section{CLINICAL DIAGNOSIS}

In view of clinical presentation, per abdominal findings and CECT findings, possibilities considered were immature teratoma ovary and small intestinal gastrointestinal stromal tumour.

\section{PATHOLOGICAL DISCUSSION}

\section{A) Macroscopy}

We received extended specimen of hemicolectomy with total abdominal hysterectomy and bilateral salpingooophorectomy. There was a nodular mass measuring $16 \times 15$ $\mathrm{cm}$, which was attached to right ovary and colon by thin membranous tissue. Cut section of mass was solid grey white with areas of haemorrhage, necrosis and calcification. Serial sections were similar (Fig. 2). Uterus was atrophic, both ovaries showed no mass lesion.

\section{B) Microscopy}

Section showed a neoplasm composed of cells arranged in sheets and nests. Individual cells were oval to spindly with moderate to scant eosinophilic cytoplasm, round to plump nuclei and clumped chromatin. Heterologous differentiation in the form of sex cord stromal elements, adipocytes, osteoid and fibromyxoid areas noted(Fig 3). Uterus showed atrophic endometrium. Ovaries showed normal histology for age. Colon showed normal histology. No infiltration of mass to adjacent structure noted.

'Financial or Other Competing Interest': None.

Submission 09-02-2019, Peer Review 10-04-2019,

Acceptance 16-04-2019, Published 22-04-2019.

Corresponding Author:

Syamini Chandrasekharapillai Leelamany,

Earathu Veedu,

Koliacode, Nemom P. 0 .,

Thiruvananthapuram-695020,

Kerala, India.

E-mail: syaminicl@gmail.com

DOI: $10.14260 /$ jemds $/ 2019 / 301$

\section{(c) $($ ) $\odot$}

\section{C) Immunohistochemistry}

Tumour cells were diffuse strong positive for CD10. Scattered positivity for cyclin D1 (Fig. 4, 5) ER, PR, Inhibin, CD117, Desmin, DOG 1 and CD 99 were negative.

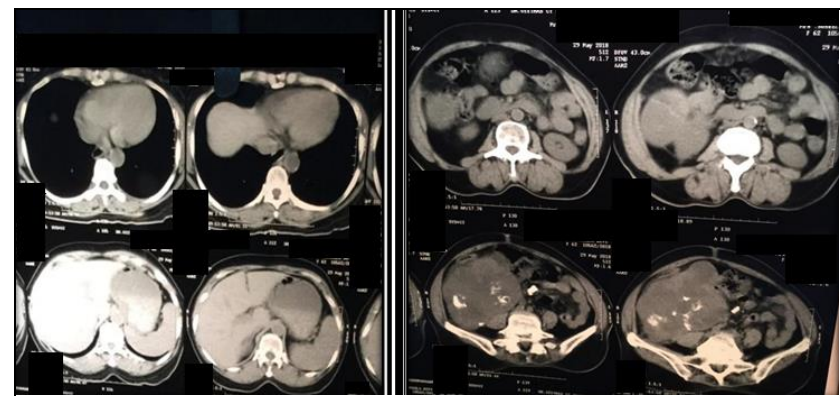

Figure 1. CECT Abdomen with Large Irregular Right Sided Pelvic Lesion

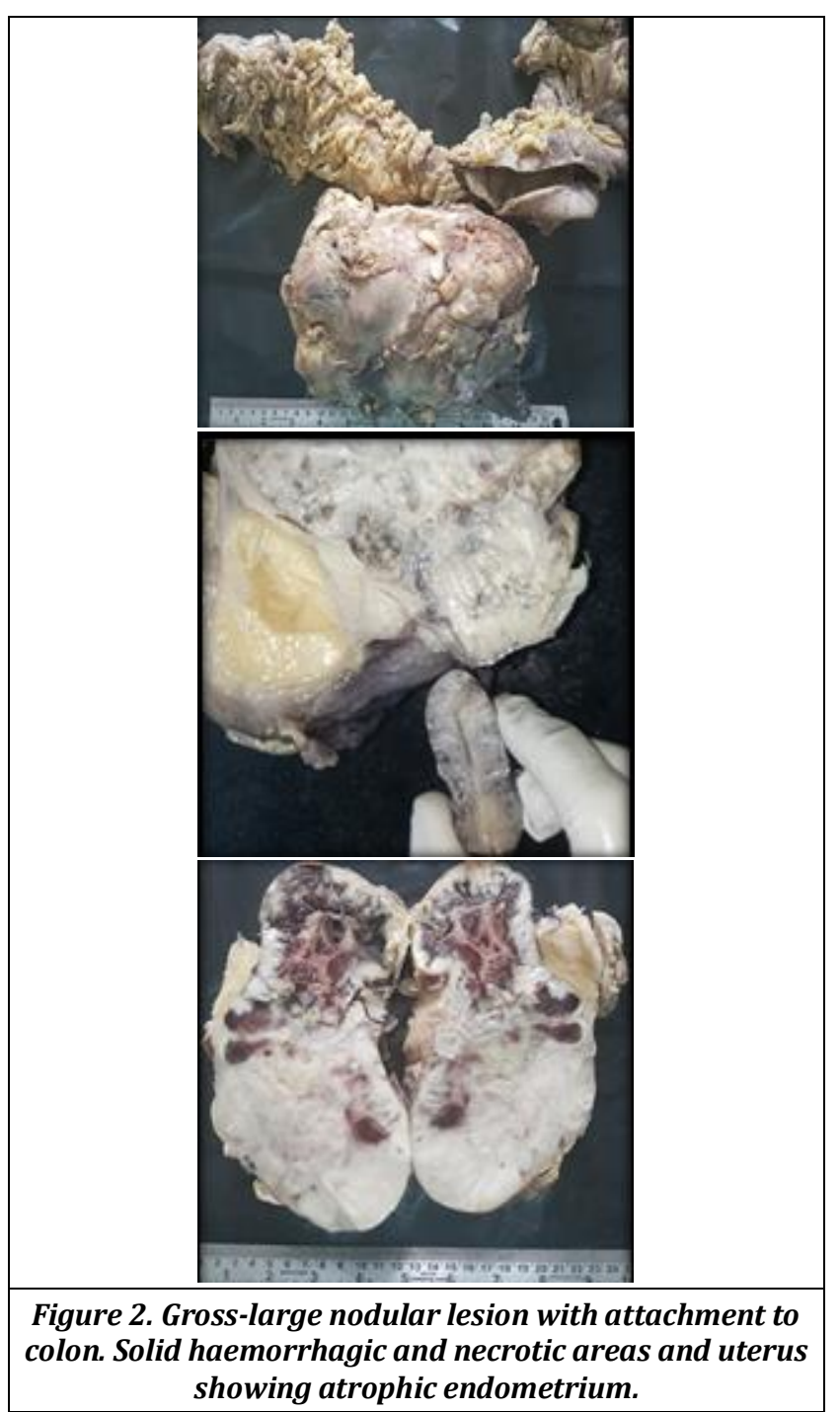



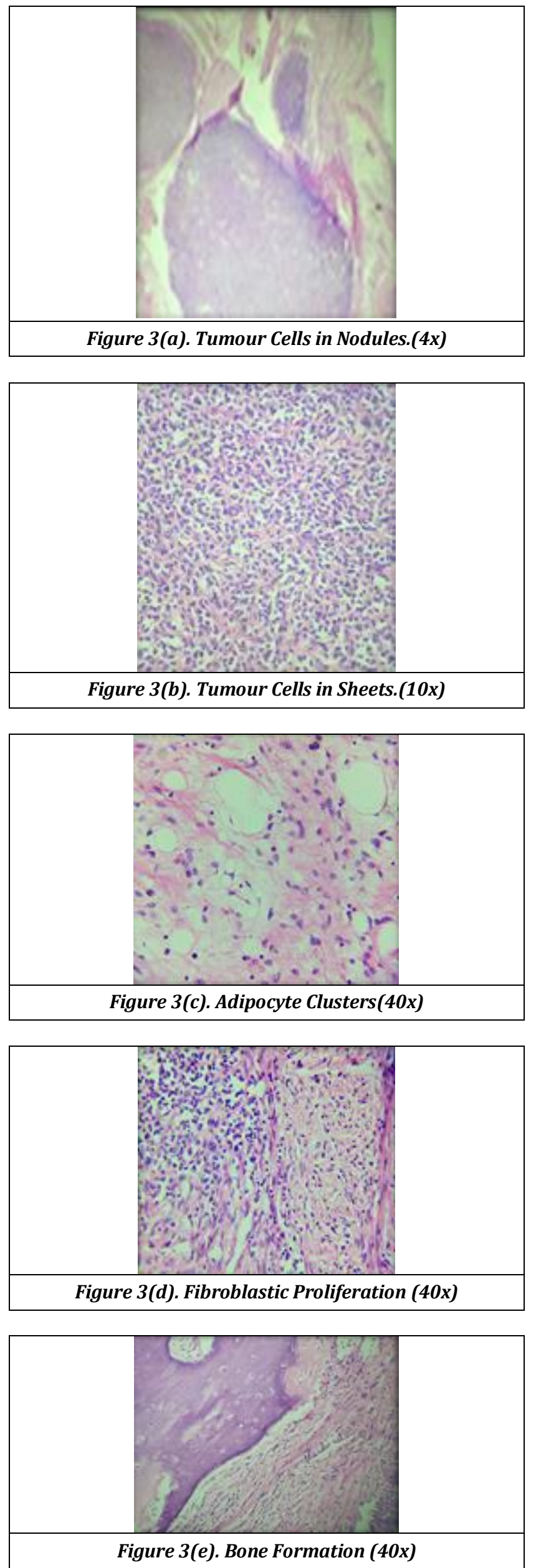
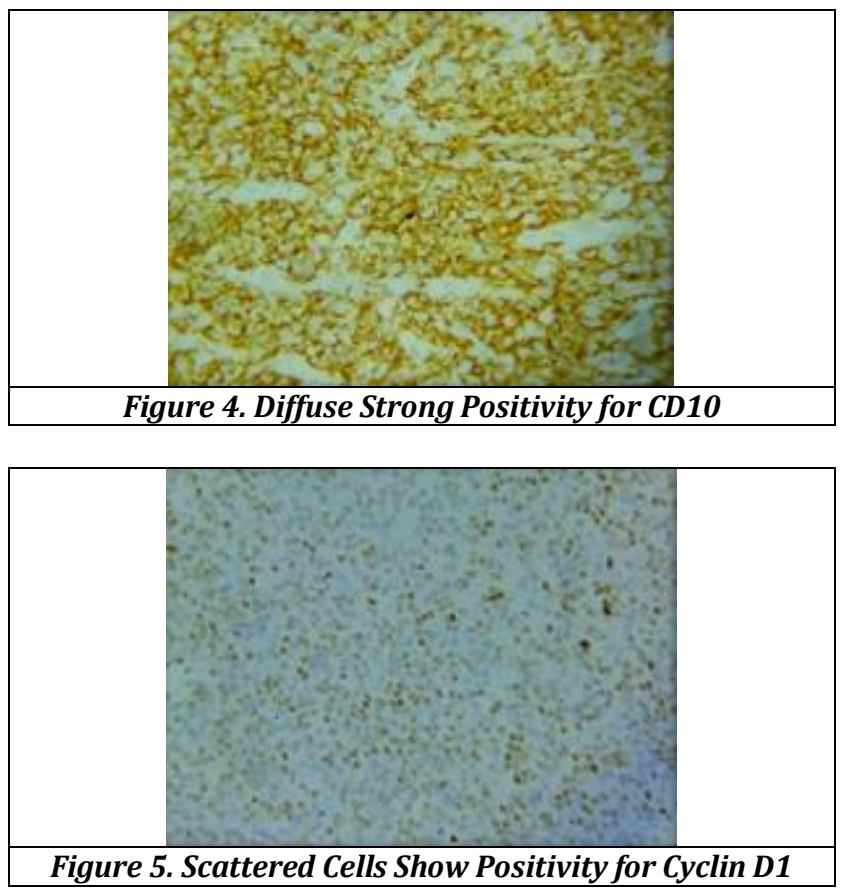

\section{DISCUSSION AND MANAGEMENT}

Primary extrauterine endometrial stromal sarcoma otherwise called endometrioid stromal sarcoma histologically resembles uterine counterpart. Primary extrauterine endometrial stromal sarcoma (ESS) is an unusual tumour and only about 80 cases have been reported thus far in literature.(1) Histologically it can be low grade or high grade based on high grade round cell morphology, infiltrative pattern and mitosis. Immunohistochemically, cells show strong positivity for CD10 and ER, PR. High grade tumours show strong diffuse positivity for cyclin D1. Genetically lowgrade shows JAZF1-SUZ12 gene fusion, EPC1- PHF1 and MEAF6-PHF1 gene rearrangement \& high grade ESS show YWHAE-FAM22 resulting from $t(10,17)(q 22$, p13).(2) Treatment is resection of nodules or mass by surgery with or without hysterectomy and ovariotomy.

Literature review showed that extrauterine endometrial stromal sarcoma is most commonly seen in premenopausal age group ${ }^{(3,4)}$ and has strong association with endometriosis.(1,5) Where as our patient was a postmenopausal woman with no history of hormonal replacement therapy and there was no evidence of endometriosis. Most of the reports showed lesions as multiple nodules or single small nodule. This patient presented with a fairly large single lesion with solid and cystic areas.

Microscopically typical histopathological features are seen with mitotic figures 2-4/HPF. Interestingly bone formation was also noted which is not a common heterologous differentiation. Extensive areas of haemorrhage and necrosis were noted which may indicate the aggressiveness of the tumour. Our case was ER, PR negative. Literature reviews showed most of low grade ESS and endometrioid stromal sarcomas were receptor status positive. $(1,5,4)$ But high-grade tumours may show absence of hormone receptor expression. Regarding chemotherapy no definite treatment protocol was described in literature, but hormonal therapy with progestins(6) and aromatase inhibitors are used in recurrent or metastatic disease, and this treatment protocol is based on receptor status positivity. 
Though rare, possibility of endometrioid stromal sarcoma to be considered in females with any spindle cell lesion of pelvis or peritoneum with or without associated endometriosis. Morphology along with IHC help in diagnosis of this entity. Molecular and genetic study is the gold standard recommended investigation. Prognosis depends on stage and grade of tumour. This case is reported in view of its occurrence in post-menopausal age group as a large solitary peritoneal lesion with heterologous osteoid differentiation, hormone receptor negativity and high-grade nature.

Since our patient was ER, PR negative, she was considered as having high grade sarcoma and is started on Ifosfamide \& Adriamycin. She succumbed to her illness 3 months after initiation of chemotherapy.

\section{DIFFERENTIAL DIAGNOSIS}

- GIST

- Leiomyosarcoma

GIST was ruled out because of negative DOG1 and CD117. Desmin negativity ruled out leiomyosarcoma.

\section{FINAL DIAGNOSIS}

Primary Extrauterine Endometrial Stromal Sarcoma- Pelvic Peritoneum

\section{REFERENCES}

[1] Ghosal T, Roy A, Kurian S. Primary extrauterine endometrial stromal sarcoma: located in pelvic and abdominal tissue and arising in endometriosis. Case Report Indian Journal of Pathology and Microbiology 2014;57(3):447-9.

[2] Rosai J. Rosai and Ackerman's Surgical Pathology. Vol. 1. 10th edn. Mosby 2011: p. 1508-09.

[3] Ayuso A, Fadare 0, Khabele D. A case of extrauterine endometrial stromal sarcoma in the colon diagnosed three decades after hysterectomy for benign disease. Case Rep Obstet Gynecol 2013;2013:202458.

[4] Kurman RJ, Carcanglu ML, Herrington CS, et al. World Health Organization classification of tumours of female reproductive organs. $4^{\text {th }}$ edn. Lyon: IARC Press 2014: p. 98-9.

[5] Masand R, Euscher ED, Deavers MT, et al. Extrauterine endometrial stromal sarcoma: a pathologic study of 63 cases with clinical correlation. Am J Surg Pathol 2013;37(11):1635-47.

[6] Zemlyak A, Hwang S, Chalas E, et al. Primary extrauterine endometrial stromal cell sarcoma: a case and review. J Gastrointest Cancer 2008;39(1-4):104-6. 